\title{
Biosorption of Acid Dye in Single and Multidye Systems onto Sawdust of Locust Bean (Parkia biglobosa) Tree
}

\author{
Abdur-Rahim Adebisi Giwa, ${ }^{1}$ Khadijat Ayanpeju Abdulsalam, ${ }^{2}$ \\ Francois Wewers, ${ }^{1}$ and Mary Adelaide Oladipo ${ }^{2}$ \\ ${ }^{1}$ Department of Chemistry, Cape Peninsula University of Technology, P.O. Box 1906, Bellville 7535, South Africa \\ ${ }^{2}$ Department of Pure and Applied Chemistry, Ladoke Akintola University of Technology, PMB 4000, Ogbomoso 210214, Nigeria
}

Correspondence should be addressed to Abdur-Rahim Adebisi Giwa; giwa1010@gmail.com and Khadijat Ayanpeju Abdulsalam; abdulsalam_khadijah@yahoo.com

Received 27 October 2015; Revised 12 January 2016; Accepted 17 February 2016

Academic Editor: Marisol Belmonte

Copyright (C) 2016 Abdur-Rahim Adebisi Giwa et al. This is an open access article distributed under the Creative Commons Attribution License, which permits unrestricted use, distribution, and reproduction in any medium, provided the original work is properly cited.

\begin{abstract}
Properties of raw sawdust of Parkia biglobosa, as a biosorbent for the removal of Acid Blue 161 dye in single, binary, and ternary dye systems with Rhodamine B and Methylene Blue dyes in aqueous solution, were investigated. The sawdust was characterized using Scanning Electron Microscopy, Fourier Transform Infrared spectrophotometry, X-ray diffraction, and pH point of zero charge. Batch adsorption experiments were carried out to determine the equilibrium characteristics, thermodynamics, and kinetics of the sorption processes. The data obtained were subjected to various isotherm and kinetics equations. The results showed that the adsorption processes were described by different isotherm models depending on the composition of the system; they were all spontaneous ( $\Delta G$ ranges from -0.72 to $-5.36 \mathrm{~kJ} / \mathrm{mol}$ ) and endothermic (range of $\Delta H$ is $11.37-26.31 \mathrm{~kJ} / \mathrm{mol}$ ) and with increased randomness with $\Delta S$ values of 55.55 and $98.78 \mathrm{~J} \cdot \mathrm{mol} / \mathrm{K}$ for single and ternary systems, respectively. Pseudo-second-order kinetics model gave better fit for all the sorption systems studied irrespective of the differences in composition, with the initial and overall rate constants higher for the mixtures than for the single system $\left(6.76 \mathrm{~g} \cdot \mathrm{mg}^{-1} \mathrm{~min}^{-1}\right)$. The presence of Rhodamine B and Methylene Blue had a synergetic effect on the maximum monolayer capacity of the adsorbent for Acid Blue 161 dye.
\end{abstract}

\section{Introduction}

Many industries make use of dyes to colour their products in order to make them more attractive; and the unspent dyes are eventually discharged as coloured wastewater into the aquatic environment [1-3], which then impart colour to water bodies. An estimated fifteen percent of the dye produced globally is lost during the dyeing process and is released into textile effluents [4]. The discharge of highly coloured effluents into natural water bodies is aesthetically displeasing and reduces light penetration, thereby affecting biological processes in the aquatic environment [5]. Some dyes used in textile industries are toxic to aquatic organisms and can be resistant to natural biological degradation. Hence, the removal of synthetic organic dyestuff from effluents is of great importance to the environment [6]. Most of the dyes are stable against photodegradation, biodegradation, and oxidizing agents $[7,8]$.
Though many methods have been employed in the remediation of dye-containing wastewater, they are associated with different shortcomings [9-11] and adsorption has been reported by overwhelmingly numerous researchers, to be very effective, simple, and versatile [11-18]. Efforts are ongoing on the search for inexpensive materials to replace the efficient but uneconomical activated carbon which has gained wide acceptance as adsorbent in the treatment of wastewater. Serious attention has been drawn to investigating low-cost materials especially agricultural wastes, the disposal of which in many cases is a challenge in many communities. Several lignocellulosic waste materials such as sugarcane bagasse and peanut biomass have been investigated for their ability to remove dyes by adsorption from aqueous solutions [19-21].

However, wastewaters from textile and other related dyeusing industries rarely contain only a single dye, but a mixture 
of dyes. As stated by Olajire et al. [22], it is very important to note that the adsorptive characteristics of a dye may be influenced by the presence of other dye(s) in the system. Comparatively few studies have been reported on the removal of dyes in multicomponent and competitive environment [22-25].

Though many economic materials such as agricultural wastes have been investigated for their ability to remove different dyes in single systems, limited studies have been reported on the adsorption of dyes in multiadsorbate systems. It is therefore the aim of this study to investigate the biosorption of Acid Blue 161 in a competitive environment using the sawdust of locust bean tree (Parkia biglobosa). Though this agrowaste has been used for the adsorption of some heavy metals (copper, lead, and nickel) and a basic dye (Rhodamine B) in single, binary, and ternary systems [24, 26], its use for the removal of any acid dye and in a multidye medium has not been reported.

\section{Materials and Methods}

2.1. Preparation of Adsorbent. The sawdust of Parkia biglobosa used in this study was collected from a popular wood industry in Ogbomoso, Nigeria. It was washed several times with distilled water, drained, dried at $105^{\circ} \mathrm{C}$ for 15 hours, sieved, and then stored as Parkia biglobosa raw sawdust (RSD).

2.2. Characterization of Adsorbent. For the characterisation of RSD, its infrared spectra were recorded before and after the adsorption of dye with a Nicolet Avatar FTIR in the range of $4000 \mathrm{~cm}^{-1}$ and $450 \mathrm{~cm}^{-1}$. The surface morphology of the adsorbent was studied with the aid of a Hitachi 2300 scanning electron microscope. X-ray diffraction analysis was conducted to determine the $\mathrm{X}$-ray diffraction patterns of the adsorbent using an X-ray diffractometer (by Philips Analytical) equipped with a monochromator and $\mathrm{CuK}$ radiation source $(40 \mathrm{kV}, 55 \mathrm{~mA})$.

The $\mathrm{pH}$ point of zero charge $\left(\mathrm{pH}_{\mathrm{zpc}}\right)$ of $\mathrm{RSD}$ was determined as reported in an earlier work by Nausheen et al. [21]. This was accomplished by adding $0.1 \mathrm{~g}$ of the adsorbent to a $200 \mathrm{~mL}$ solution of $0.1 \mathrm{M} \mathrm{NaCl}$ of predetermined initial $\mathrm{pH}\left(\mathrm{pH}_{i}\right)$. The initial $\mathrm{pH}$ of $\mathrm{NaCl}$ solutions in different flasks to which the adsorbent was added was adjusted with $0.1 \mathrm{M} \mathrm{NaOH}$ or $\mathrm{HCl}$. The flasks were covered and shaken for 24 hours after which the final $\mathrm{pH}\left(\mathrm{pH}_{f}\right)$ was measured using a Jenway $\mathrm{pH}$ meter. A plot of change in $\mathrm{pH}\left(\mathrm{pH}_{i}-\mathrm{pH}_{f}\right)$ against initial $\mathrm{pH}$ gives $\mathrm{pH}_{\mathrm{zpc}}$ where the plot crosses the horizontal axis [27].

2.3. Preparation of Adsorbate. The primary adsorbate in this study is an anionic dye, Acid Blue 161 (AB), by M \& B Laboratory Chemicals. Working aqueous solutions of different concentrations of Acid Blue 161 dye were prepared from the stock solution of the dye $(1000 \mathrm{mg} / \mathrm{L})$ in the single dye system. In the binary system, either Rhodamine B (RB) dye or Methylene Blue (MB) dye was present in predetermined concentrations with the primary adsorbate, Acid Blue 161 dye. All three dyes were present as a mixture in the ternary system. Figure 1 gives the structure of the three dyes.
2.4. Batch Adsorption Experiments. A series of $50 \mathrm{~cm}^{3}$ solutions of different concentrations of Acid Blue 161 dye were added to a fixed mass of RSD in clearly labelled glass bottles with lids and were agitated in a Uniscope thermostated horizontal mechanical shaker (SM 101 by Surgifriend Medicals) at a constant speed, temperature, and $\mathrm{pH}$, until equilibrium was attained. Additional series of batch experiments were performed to study the effects of RSD dose, contact time, and temperature using different masses of RSD, predetermined contact times, and temperature, respectively. The dye-RSD mixtures in the various flasks were filtered and the absorbance of the filtrate was measured with a GENESYS 10 UV-Visible Scanning Spectrophotometer at the predetermined absorption wavelength, $\lambda_{\max }$, of Acid Blue 161 dye $(610 \mathrm{~nm})$.

The amount of dye adsorbed per unit mass of RSD (i.e., adsorption capacities of RSD), $q$ (mg/g), was evaluated using the following equations:

$$
\begin{aligned}
& q_{e}=\frac{\left(C_{o}-C_{e}\right) V}{m}, \\
& q_{t}=\frac{\left(C_{o}-C_{t}\right) V}{m},
\end{aligned}
$$

where $q_{e}$ and $q_{t}$ are the amount of dye adsorbed $(\mathrm{mg} / \mathrm{g})$ at equilibrium and at time $t$, respectively; $C_{o}, C_{e}$, and $C_{t}(\mathrm{mg} / \mathrm{L})$ are the initial concentration of dye (at $t=0)$, concentration of dye at equilibrium, and its concentration at time $t=t$, respectively; $V$ is the volume of the solution (L); and $m$ is the mass of $\operatorname{RSD}(\mathrm{g})$.

\section{Results and Discussion}

3.1. Characterization of RSD. FTIR spectra of RSD before and after adsorption of dyes are shown in Figure 2. Parkia biglobosa sawdust is a complex natural material as its FTIR spectrum presents several absorption peaks even before the adsorption of any dye (Figure 2(a)). As expected of a cellulosic, hemicellulosic, or lignin material, the spectrum displays diagnostic bands at $3417 \mathrm{~cm}^{-1}, 1647 \mathrm{~cm}^{-1}$, and $1734 \mathrm{~cm}^{-1}$ which can be assigned to bonded $-\mathrm{OH}$, aromatic $\mathrm{C}=\mathrm{C}$, and carbonyl $(\mathrm{C}=\mathrm{O})$ functional groups, respectively. These are likely adsorption sites for the chemisorption of an adsorbate $[4,20]$.

After adsorption of Acid Blue 161, the FTIR spectrum of the adsorbent showed that there are shifts in the position of some bands to higher frequencies (Figure 2(b)). These include the shift in the band assigned to $-\mathrm{OH}$ from $3417 \mathrm{~cm}^{-1}$ to $3421 \mathrm{~cm}^{-1}$ and $\mathrm{C}=\mathrm{O}$ band from $1647 \mathrm{~cm}^{-1}$ to $1653 \mathrm{~cm}^{-1}$. A new band was noticed at $3726 \mathrm{~cm}^{-1}$ after the adsorption of the dye. This can be assigned to the $\mathrm{O}-\mathrm{H}$ stretching vibration, possibly from water molecules of the dye solution. These shifts in adsorption bands suggest some kind of chemical interaction between the surface of RSD and the dye molecules.

Other results of characterization are presented in Figure 3. The scanning electron micrograph of RSD recorded at $\times 1000$ magnification is depicted in Figure $3(\mathrm{a})$. The image reveals an irregular and porous surface topography of the adsorbent. This may be a pointer to a high surface area of 


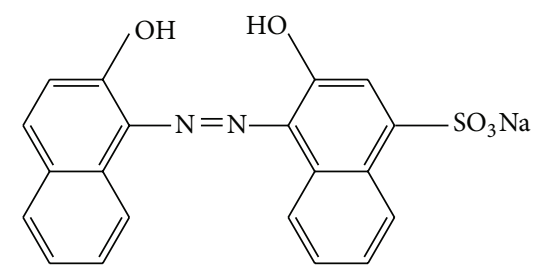

(a)<smiles></smiles>

(b)<smiles>CCCCCCNc1ccc2c(c1)C(c1ccccc1C(=O)O)C1C=CC(=NCCCC)C=C1O2</smiles>

(c)

Figure 1: Structures of (a) Acid Blue 161, (b) Methylene Blue, and (c) Rhodamine B.

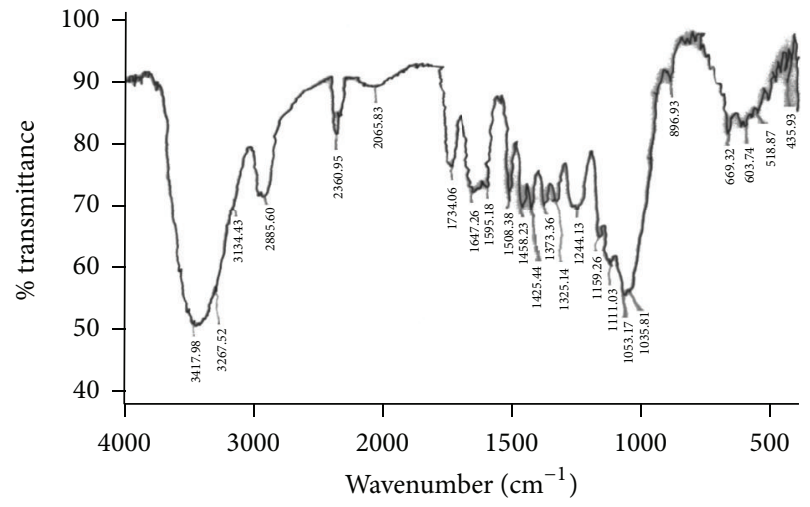

(a)

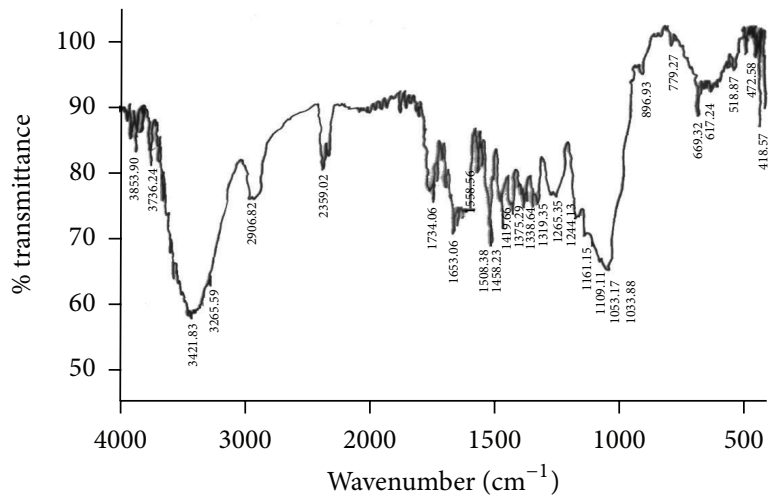

(b)

FIGURE 2: FTIR spectra of RSD (a) before and (b) after adsorption of Acid Blue 161.

the material, a quality of a good adsorbent $[26,28]$. The $\mathrm{pH}$ at the point of zero charge, $\mathrm{pH}_{\mathrm{zpc}}$, is 7.83 as shown in Figure 3(b). At any $\mathrm{pH}$ below this value, the surface of the adsorbent should be positively charged and will attract negatively charged species in the solution. At $\mathrm{pH}$ above $\mathrm{pH}_{\mathrm{zpc}}$ of the adsorbent, the surface of the adsorbent is negatively charged and attracts cations [29]. The X-ray diffraction patterns of RSD adsorbent are presented in Figure 3(c). The patterns were obtained by continuous scanning type from 5.04 to $60^{\circ}$. Raw results obtained were recorded using the PC-APD software. One sharp peak was recorded at $2 \theta$ value of 23.6 with the highest intensity, while two broad peaks were observed around 34.7 and 46.62 (Figure 3(c)).

3.2. Effects of Adsorbent Dose on Acid Dye Adsorption. Specific uptake of Acid Blue 161, $q_{e}$ (i.e., adsorption of Acid Blue 161 per unit mass of adsorbent), decreased with increasing dose of RSD for all the adsorbate systems (single, binary, and ternary systems) studied as shown in Figure 4. As the dose of RSD increased from 0.1 to $0.6 \mathrm{~g}$, the adsorption capacity, $q_{e}$, decreased steadily from 10.32 to $1.841 \mathrm{mg} / \mathrm{g}$ in single dye system containing Acid Blue 161 only; from 7.55 to $2.12 \mathrm{mg} / \mathrm{g}$ in the binary system comprising Acid Blue 161 and Rhodamine $\mathrm{B}(\mathrm{AB}+\mathrm{MB})$; and from 10.36 to $1.79 \mathrm{mg} / \mathrm{g}$ in the binary system consisting of Acid Blue 161 and Methylene Blue (AB + $\mathrm{RB}$ ). A decrease in the uptake density (7.59 to $1.69 \mathrm{mg} / \mathrm{g}$ ) was also observed in the ternary system where all the three dyes were present. These observations may be due to the effective utilization of active sites on the surface of RSD at low doses. But a sizeable portion of the available active sites on the adsorbent may have overlapped as adsorbent dose increased, resulting in reduced specific uptake recorded. Similar observations have been reported elsewhere for the adsorption of Rhodamine B in single, binary, and ternary systems by Giwa et al. [24] and other sorption processes [29-31].

3.3. Effects of Solution $\mathrm{pH}$ on Acid Dye Adsorption. The $\mathrm{pH}$ of an aqueous system controls the speciation and degree of ionization of the adsorbate in an adsorption process. It is therefore a very important factor in adsorptive remediation 


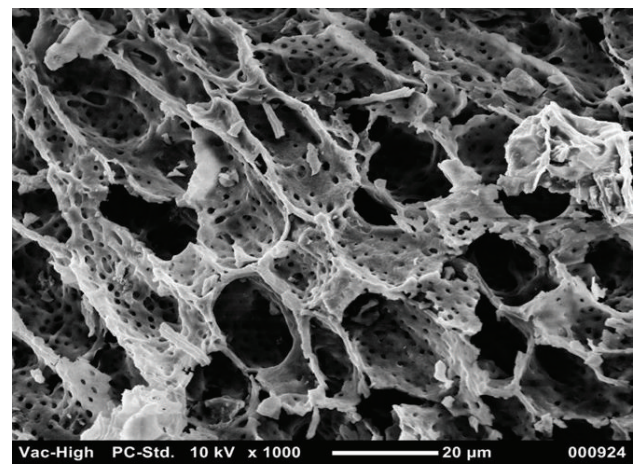

(a)

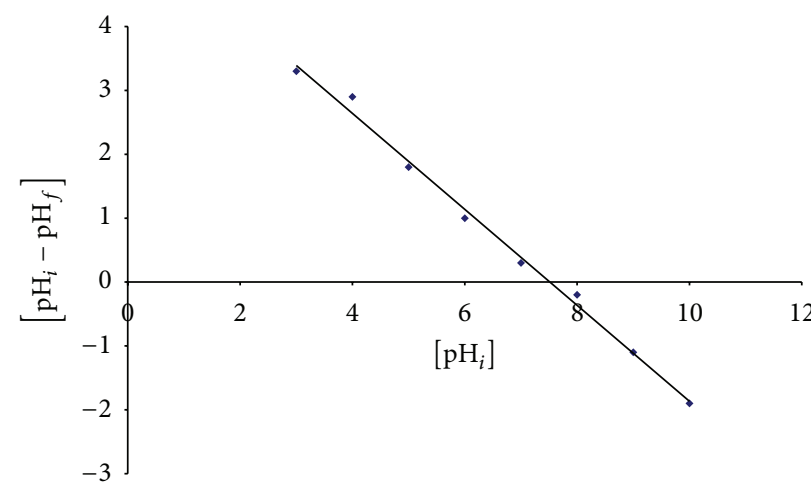

(b)

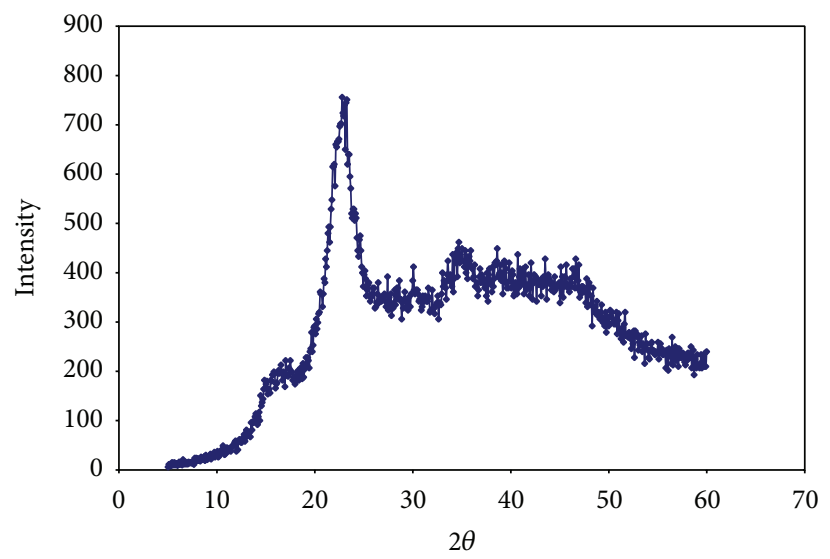

(c)

FIGURE 3: (a) SEM image (magnification: $\times 1000$ ), (b) $\mathrm{pH}$ point of zero charge $\left(\mathrm{pH}_{\mathrm{zpc}}\right.$ ) plot, and (c) X-ray diffraction patterns of RSD.

of wastewater. The effect of $\mathrm{pH}$ on the adsorption of Acid Blue 161 on RSD is presented in Figure 5. The adsorption capacity, $q_{e}$, was relatively high in the acidic $\mathrm{pH}$ region, attaining its maximum at around 3 and reducing with increasing $\mathrm{pH}$ afterwards. This may be due to the increase in $\mathrm{OH}^{-}$ions competing with the anion groups on the dye for adsorption sites on $\mathrm{RSD}$, with an increase in $\mathrm{pH}$. Also, at $\mathrm{pH}$ below $\mathrm{pH}_{\mathrm{zpc}}$ of the adsorbent, the surface of the adsorbent is positively charged and thereby electrostatically attracts anionic dyes [29]; and this enhances the adsorption of Acid Blue 161. Similar observations on high adsorption capacity of acid dye at acidic $\mathrm{pH}$ values have been reported by Hameed et al. [30] and Yang et al. [32].

3.4. Effects of Initial Dye Concentrations on Acid Blue 161 Adsorption. In investigating the effects of initial concentration of Acid Blue 161 on its adsorption onto RSD, a total of six different adsorbate systems were considered, with the series of initial concentrations of Acid Blue 161 being the same in all: (i) Acid Blue 161 only (single system), (ii) Acid Blue 161 together with $10 \mathrm{mg} / \mathrm{L}$ Methylene Blue $\left(\mathrm{AB}+\mathrm{MB}_{1}\right.$, binary system), (iii) Acid Blue 161 together with $20 \mathrm{mg} / \mathrm{L}$ Methylene Blue $\left(\mathrm{AB}+\mathrm{MB}_{2}\right.$, binary system), (iv) Acid Blue 161 together with $10 \mathrm{mg} / \mathrm{L}$ Rhodamine $\mathrm{B}\left(\mathrm{AB}+\mathrm{RB}_{1}\right.$, binary system), (v) Acid Blue 161 together with $20 \mathrm{mg} / \mathrm{L}$ Rhodamine $\mathrm{B}(\mathrm{AB}+$ $\mathrm{RB}_{2}$, binary system), and (vi) a mixture of Acid Blue 161 and
$20 \mathrm{mg} / \mathrm{L}$ of Methylene Blue and $20 \mathrm{mg} / \mathrm{L}$ of Rhodamine B $(\mathrm{AB}+\mathrm{MB}+\mathrm{RB})$.

The adsorption capacity of RSD for Acid Blue 161 (i.e., adsorption of Acid Blue 161 per unit mass of RSD) increased with increasing initial concentration of Acid Blue 161 for all the adsorbate-adsorbent systems whether single, binary, or ternary system, as shown in Figure 6. As the initial concentration of Acid Blue 161 increased from $10 \mathrm{mg} / \mathrm{L}$ to $100 \mathrm{mg} / \mathrm{L}$, $q_{e}$ increased from 4.48 to $20.61 \mathrm{mg} / \mathrm{g}$ in the $\mathrm{AB}$ single dye system, from 4.32 to $28.60 \mathrm{mg} / \mathrm{g}$ in $\mathrm{AB}+\mathrm{MB}_{1}$ binary system, from 3.96 to $22.81 \mathrm{mg} / \mathrm{g}$ in $\mathrm{AB}+\mathrm{MB}_{2}$ binary system, from 4.39 to $21.87 \mathrm{mg} / \mathrm{g}$ in $\mathrm{AB}+\mathrm{RB}_{1}$ binary system, from 4.35 to $20.76 \mathrm{mg} / \mathrm{g}$ in $\mathrm{AB}+\mathrm{RB}_{2}$ binary system, and from 4.24 to $19.71 \mathrm{mg} / \mathrm{g}$ in the ternary dye system. The observed increase in the specific uptake of the dye with increasing initial dye concentration in all the systems may be because, at low concentrations, the number of dye molecules available is low, but, at higher concentrations, the number of dye molecules available is high enough to overcome resistance to mass transfer. Bello et al. [33] and Giwa et al. [26] reported similar observations.

At low but equal initial concentrations of Acid Blue 161 dye, there were marginal increases in adsorption capacity with decreasing concentration of the competing dye. For example, at $10 \mathrm{mg} / \mathrm{L}$ initial Acid Blue 161 concentration, adsorption capacity of RSD for the dye was 4.48, 4.32, 4.39, and $4.35 \mathrm{mg} / \mathrm{g}$ for single, $\mathrm{AB}+\mathrm{MB}_{1}, \mathrm{AB}+\mathrm{RB}_{2}, \mathrm{AB}+\mathrm{RB}_{1}$, 
TABLE 1: Kinetics parameters for adsorption of Acid Blue 161 onto raw sawdust.

\begin{tabular}{lccccccc}
\hline $\begin{array}{l}\text { Adsorbate } \\
\text { system }\end{array}$ & $q_{e, \exp }$ & $R^{2}$ & $q_{e, \text { calc }}$ & $k_{1}$ & $R^{2}$ & $q_{e, \text { calc }}$ & $k_{2}$ \\
\hline $\mathrm{AB}$ & 10.38 & 0.866 & 3.55 & 0.159 & 0.998 & 11.11 & 0.055 \\
$\mathrm{AB}+\mathrm{MB}$ & 11.31 & 0.976 & 1.10 & 0.119 & 0.999 & 11.49 & 0.216 \\
$\mathrm{AB}+\mathrm{RB}$ & 10.97 & 0.980 & 0.51 & 0.046 & 0.999 & 11.11 & 0.219 \\
$\mathrm{AB}+\mathrm{MB}+\mathrm{RB}$ & 11.51 & 0.701 & 1.08 & 0.087 & 0.998 & 11.90 & 0.118 \\
\hline
\end{tabular}

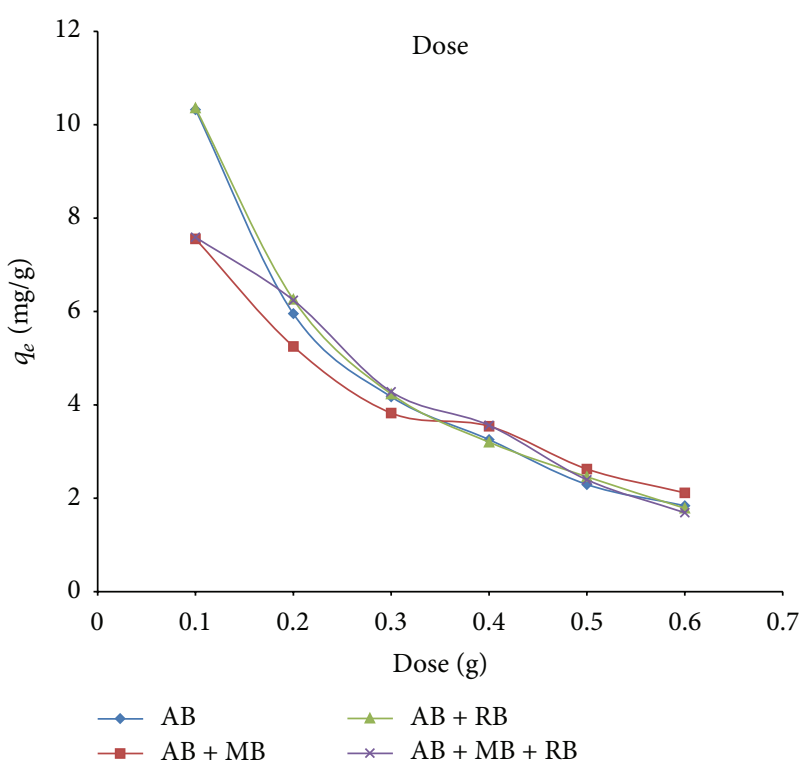

FIGURE 4: Effects of RSD dose on adsorption of Acid Blue 161 on raw sawdust.

and $A B+R B_{2}$ systems, respectively. This may be due to the competitive nature of the adsorption processes.

3.5. Effects of Contact Time and Kinetics. Adsorption of Acid Blue 161 in single, binary, and ternary dye systems increased as contact time increased (Figure 7) until equilibrium was attained. Equilibrium was reached relatively faster in binary and ternary systems than in the single dye system. This may be due to the contribution of concentration to the rate of the reactions. Though the initial concentration of Acid Blue 161 which is the focus of the study was the same in all the systems, the total concentrations of dyes in the mixture systems were higher than in the single system ( $\mathrm{AB}$ only) as a result of the presence of the other dyes (Rhodamine $\mathrm{B}$ and/or Methylene Blue) in the mixture $(\mathrm{AB}+\mathrm{MB}, \mathrm{AB}+\mathrm{RB}$, and $\mathrm{AB}+\mathrm{MB}+$ $\mathrm{RB})$.

The study of adsorption dynamics describes the solute uptake rate and evidently this rate controls the residence time of adsorbate uptake at the solid-solution interface. The kinetics of the adsorption of Acid Blue 161 were examined using the pseudo-first-order model [34] and pseudo-second-order equation by Ho et al. [35]. The linear forms of the models are given as follows.

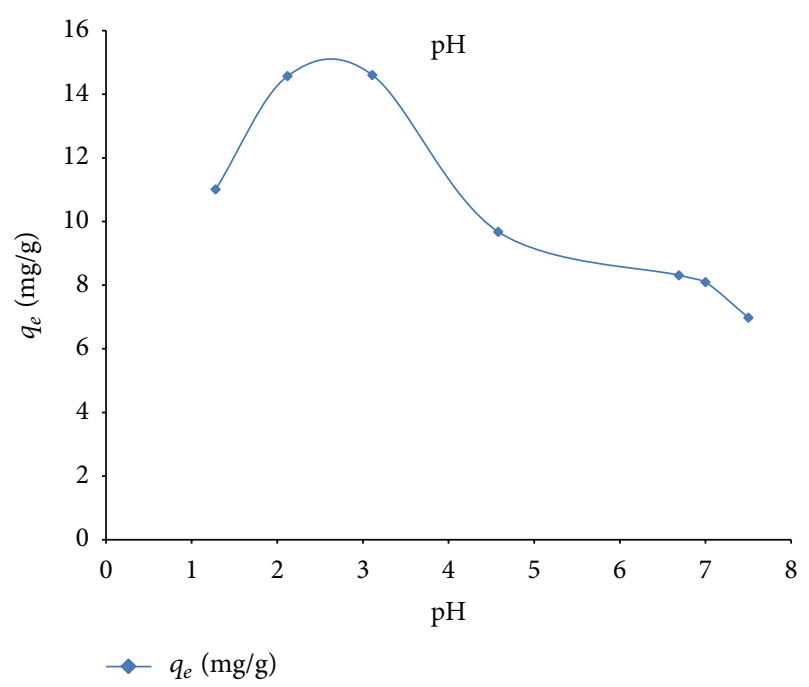

Figure 5: Effects of $\mathrm{pH}$ on adsorption of Acid Blue 161 on raw sawdust.

The pseudo-first-order equation is given as follows:

$$
\ln \left(q_{e}-q_{t}\right)=\ln \left(q_{e}\right)-k_{1} t .
$$

The pseudo-second-order equation is given as follows:

$$
\frac{t}{q_{t}}=\frac{1}{k_{2} q_{e}^{2}}+\frac{1}{q_{e}} t
$$

where $q_{t}$ is the adsorption capacity at time $t\left(\mathrm{mg} \cdot \mathrm{g}^{-1}\right), k_{1}$ is the rate constant of pseudo-first-order adsorption $\left(\mathrm{min}^{-1}\right)$, and $k_{2}\left(\mathrm{~g} \cdot \mathrm{mg}^{-1} \mathrm{~min}^{-1}\right)$ is the pseudo-second-order rate constant.

The linear plots of the two equations are shown in Figure 8, and the rate parameters obtained thereof are given in Table 1. The kinetics of adsorption for all the four adsorbate systems (one single system, two binary systems, and one ternary system) are best described by the pseudo-secondorder rate model. They all have high $R^{2}$ values $>0.99$. In addition to this, there is a better agreement between the experimental and calculated values of $q_{e}$ for pseudo-second-order model than for pseudo-first-order model (Table 1). The conformation of the kinetics of the sorption processes to pseudosecond-order equation suggests a rate limiting step involving chemisorption $[36,37]$. The pseudo-second-order overall rate constant, $k_{2}\left(\mathrm{~g} \cdot \mathrm{mg}^{-1} \mathrm{~min}^{-1}\right)$, and the initial rate constant, $h$, are both higher for the dye mixtures than for the single Acid Blue 161 dye system. 
TABLE 2: Isotherm parameters for the adsorption of Acid Blue 161 onto raw sawdust.

\begin{tabular}{lccccccccc}
\hline $\begin{array}{l}\text { Adsorbate } \\
\text { system }\end{array}$ & \multicolumn{3}{c}{ Langmuir } & \multicolumn{3}{c}{ Freundlich } & \multicolumn{3}{c}{ Temkin and Pyzhev } \\
\hline $\mathrm{AB}$ & 0.991 & 40.0 & 0.02 & 0.998 & 1.48 & 0.651 & 0.924 & 4.12 \\
$\mathrm{AB}+\mathrm{MB}$ & 0.982 & 100 & 0.5 & 0.983 & 13.84 & 0.284 & 0.999 & 417.79 \\
$\mathrm{AB}+\mathrm{RB}$ & 0.964 & 100 & 0.25 & 0.991 & 10.09 & 0.213 & 0.855 & 133.05 & 1.22 \\
$\mathrm{AB}+\mathrm{MB}+\mathrm{RB}$ & 0.954 & 94.3 & 0.28 & 0.904 & 3.69 & 0.237 & 0.848 & 10.41 \\
\hline
\end{tabular}

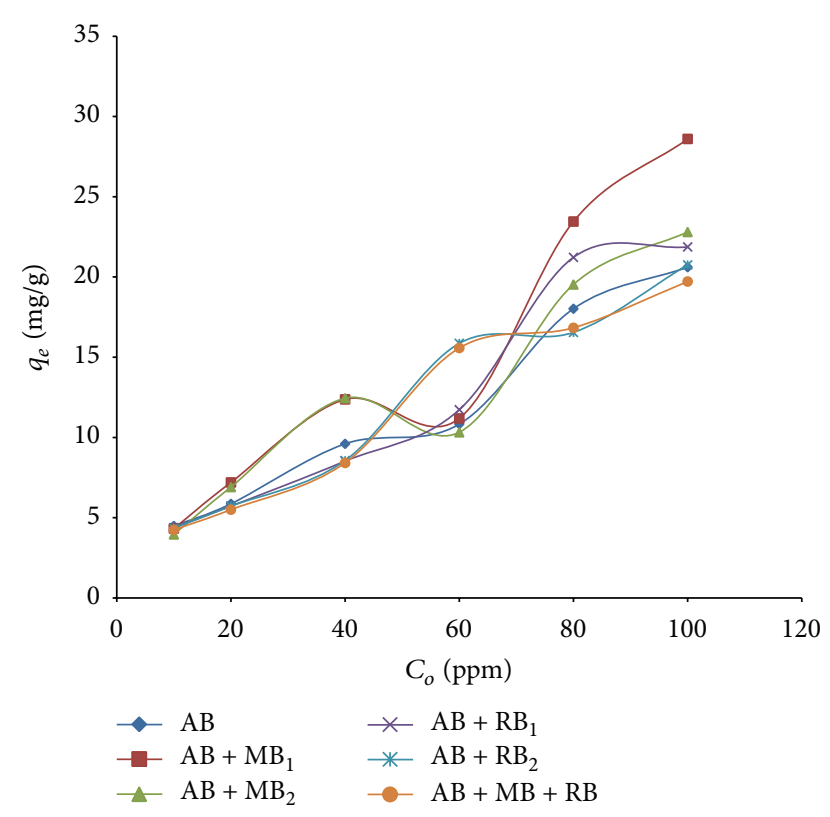

FIGURE 6: Effects of initial dye concentration on adsorption of Acid Blue 161 on RSD.

3.6. Adsorption Isotherm Modelling. The adsorption equilibrium isotherm gives the relationship between the adsorbates in the liquid phase and on the surface of the adsorbent at equilibrium at constant temperature. In this study, the equilibrium concentrations of the residual Acid Blue 161 dye solution $\left(C_{e}\right)$ and the various amounts of the dye adsorbed on the surface of RSD $\left(q_{e}\right)$ for single, binary, and ternary systems were modelled after the linear forms of Langmuir (1918) [38], Freundlich (1906) [39], and Temkin and Pyzhev (1940) [40] isotherm equations so as to describe the equilibrium relationship at constant temperature. Comparative applicability of the isotherm models was determined using the correlation coefficients, $R^{2}$, of the linear plots. The linear forms of the equations applied in this study are given below.

Langmuir model is given as follows:

$$
\frac{C_{e}}{q_{e}}=\frac{1}{K_{a} q_{m}}+\frac{C_{e}}{q_{m}}
$$

Freundlich isotherm is given as follows:

$$
\log q_{e}=\log K_{F}+\log C_{e} .
$$

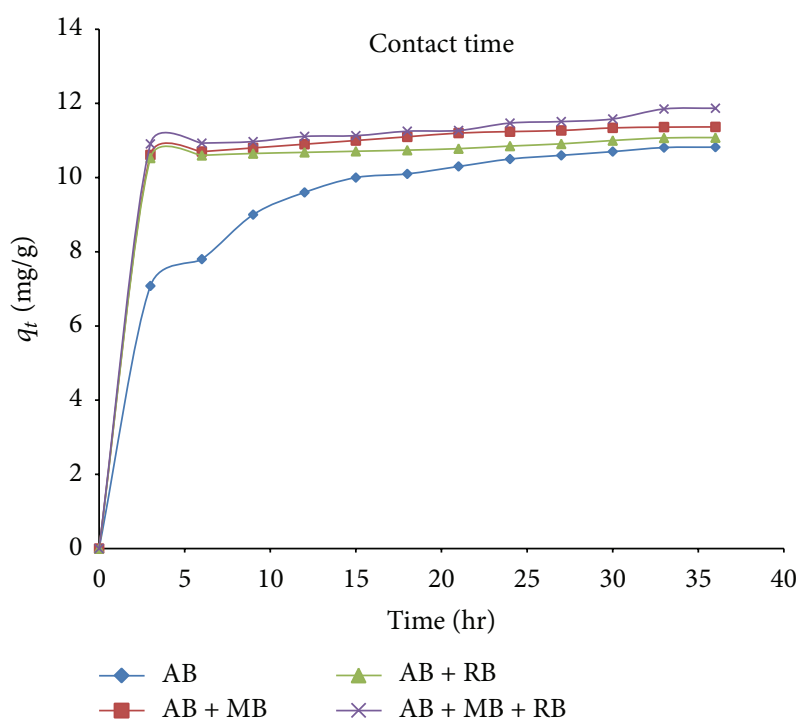

FIGURE 7: Effects of contact time on the adsorption of Acid Blue 161 on raw sawdust.

Temkin and Pyzhev model is given as follows:

$$
q_{e}=\frac{R T}{b_{T}} \ln A_{T}+\frac{R T}{b_{T}} \ln C_{e},
$$

where $C_{e}$ is the equilibrium concentration of adsorbate $(\mathrm{mg} / \mathrm{L}) ; q_{e}$ is the amount of adsorbate absorbed per unit mass of adsorbate $\left(\mathrm{m} \cdot \mathrm{gg}^{-1}\right) ; q_{m}$ and $K_{a}$ are Langmuir constants related to monolayer adsorption capacity and affinity of adsorbent towards adsorbate, respectively; $K_{F}$ is the Freundlich constant which is an indicator of the adsorption capacity related to bond energy and is the adsorption intensity on the adsorbent or surface heterogeneity; $A_{T}$ and $b_{T}$ are Temkin and Pyzhev constants; $R$ is the universal gas constant $\left(8.314 \mathrm{~J} \cdot \mathrm{mol}^{-1} \mathrm{~K}^{-1}\right)$; and $T$ is the temperature in kelvin $[31,41$, 42].

The equilibrium isotherm parameters obtained from the linear plots of the linearized isotherm equations together with their respective correlation coefficients for the adsorption processes are given in Table 2.

The coefficients of correlation, $R^{2}$, presented in Table 2 are high for the three isotherm models, implying that the adsorption processes exhibit different characteristics at different stages, which influenced the final mechanism. This is an indication that the adsorption of Acid Blue 161 is a complex process. 


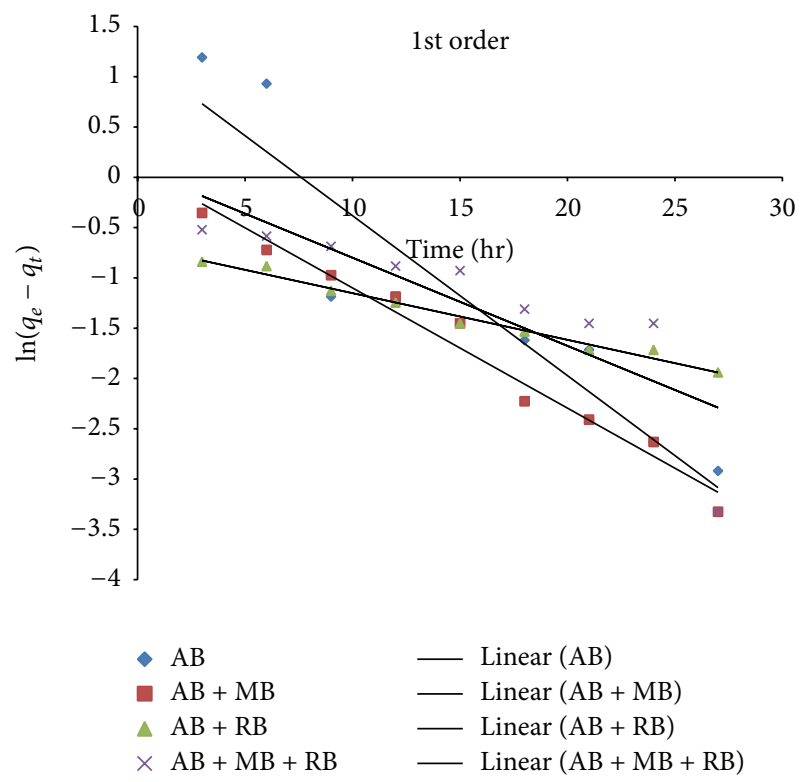

(a)

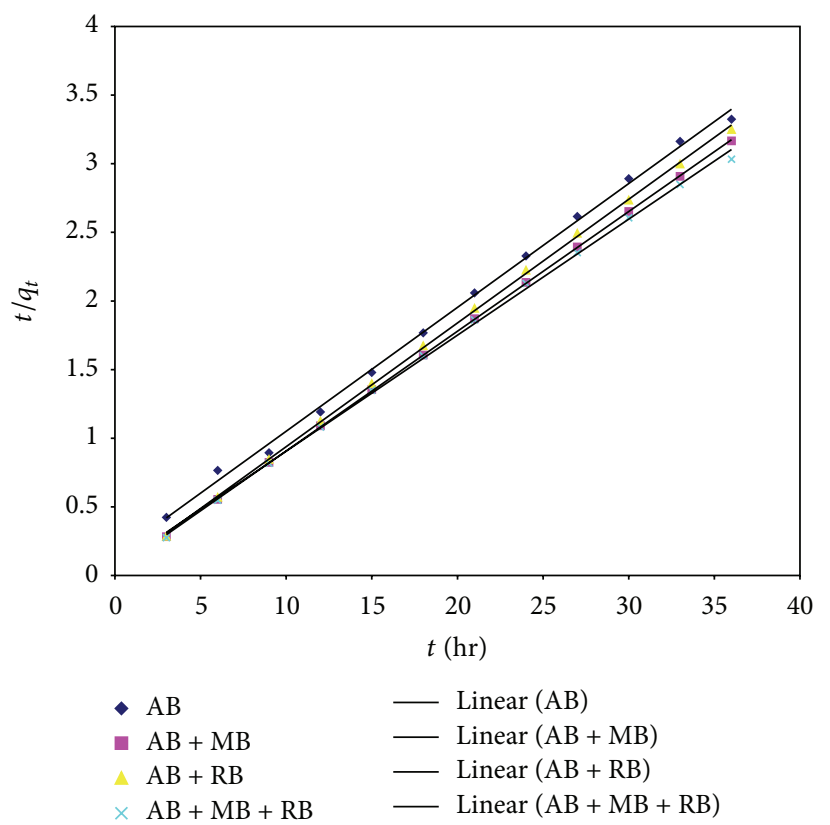

(b)

FIGURE 8: Plots of (a) pseudo-first-order and (b) pseudo-second-order kinetics for adsorption of Acid Blue 161 onto RSD in single and mixture systems.

Langmuir isotherm model assumes monolayer adsorption onto a finite number of adsorption sites on the surface of an adsorbent and with no transmigration of adsorbate in the plane of surface [43]. The Langmuir maximum monolayer coverage, $q_{m}$, for the adsorption processes in this study was relatively low (40 mg/g) for the single Acid Blue 161 adsorbate system when compared with the two binary and ternary systems which have values of $100 \mathrm{mg} / \mathrm{g}$ and $94.34 \mathrm{mg} / \mathrm{g}$, respectively (Table 2 ). This shows that, with respect to the monolayer adsorption capacity, the presence of Rhodamine B and Methylene Blue dyes in the system has a synergetic effect on the adsorption of Acid Blue 161. This, however, is contrary to the report on the adsorption of Methylene Blue on melon husk in single and ternary dye systems with two acid dyes where the monolayer capacity was higher in single system than in ternary dye system [22]. The Langmuir constant, $K_{a}$, a measure of the affinity between adsorbate and adsorbent which is related to free energy of adsorption [44], was higher in mixture systems than in the single system $(0.018 \mathrm{~L} / \mathrm{g})$ (Table 2). The synergetic effect was more pronounced with Methylene Blue $(0.5 \mathrm{~L} / \mathrm{g})$ than with Rhodamine B $(0.25 \mathrm{~L} / \mathrm{g})$. Though both dyes are classified as basic, Rhodamine B can behave in an "amphoteric" manner depending on the medium. This is also evident in the ternary system where the value for the Langmuir constant $(0.275 \mathrm{~L} / \mathrm{g})$ was between those of Methylene Blue and Rhodamine B binary systems, respectively (Table 2 ).

As for the Freundlich model, $R^{2}$ values for the adsorption processes are high (0.904-0.998) (Table 2), suggesting possible heterogeneous nature of the RSD surface and the possibility of multilayer adsorption on it. The Freundlich constant, $K_{F}$, is an empirical constant, which indicates the sorption capacity of adsorbents in $\mathrm{mg} / \mathrm{g}$. This constant is higher in binary and ternary dye mixture than in the single Acid Blue 161 system (Table 2 ). A high $K_{F}$ value may also indicate that the rate of adsorbate removal is high [45]. Again, the binary dye system with Methylene Blue gave the highest $K_{F}$ value, in agreement with the results obtained from Langmuir model (Table 2). The values of $1 / n$, another Freundlich constant which is a measure of adsorption intensity or surface heterogeneity, are below 1 for all the adsorption processes under investigation. This implies favourable adsorption processes [44].

The Temkin and Pyzhev isotherm is considered so as to investigate the energy relationship in the Acid Blue 161 and RSD interaction. Since $R^{2}$ values obtained from the plots of the isotherm equation are also high, the model is suitable for the processes involved. It can, therefore, be deduced that the energy associated with the adsorption of Acid Blue 161 dye in all the systems decreases linearly with coverage as assumed by the Temkin and Pyzhev isotherm model [46]. This also suggests that there were adsorbate-adsorbate interactions in the processes of the adsorption under study (Table 2). Values obtained for Temkin and Pyzhev parameter $A_{T}$, which is a measure of the adsorption potential, are higher in the mixture systems than in single Acid Blue 161 system. This follows the same trend as recorded for the Langmuir isotherm (Table 2). The constant $b_{T}$, which relates to energy of adsorption, has its values between 0.35 and $1.92 \mathrm{~kJ} / \mathrm{mol}$. This is lower than the range $8-16 \mathrm{~kJ} / \mathrm{mol}$ associated with bonding energy for ionexchange mechanism in adsorption [34]. This implies that the association between Acid Blue 161 and RSD adsorbent in all the four adsorbate-adsorbent systems under study might not involve an ion-exchange mechanism but may be 


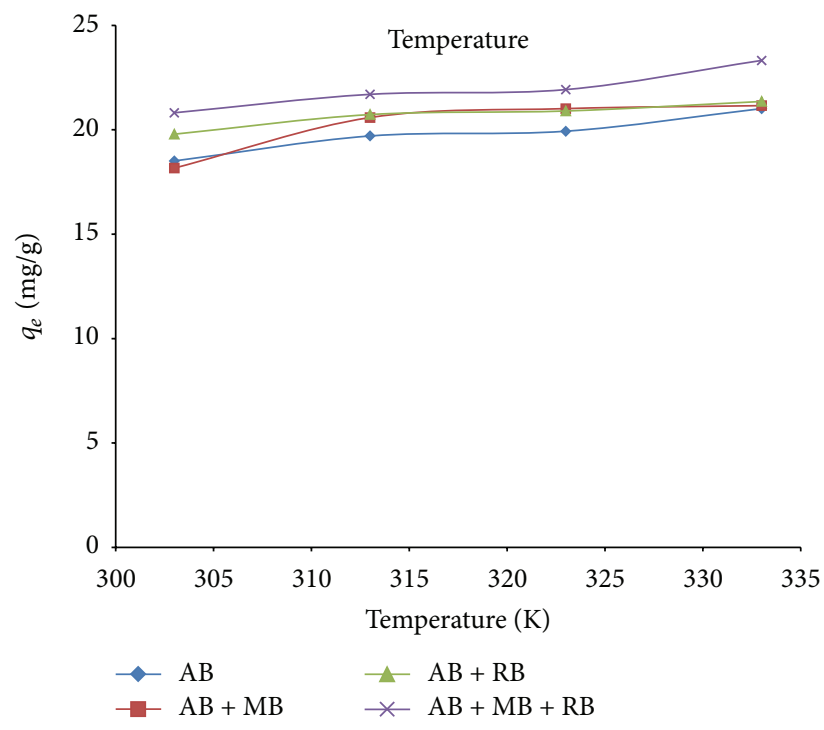

(a)

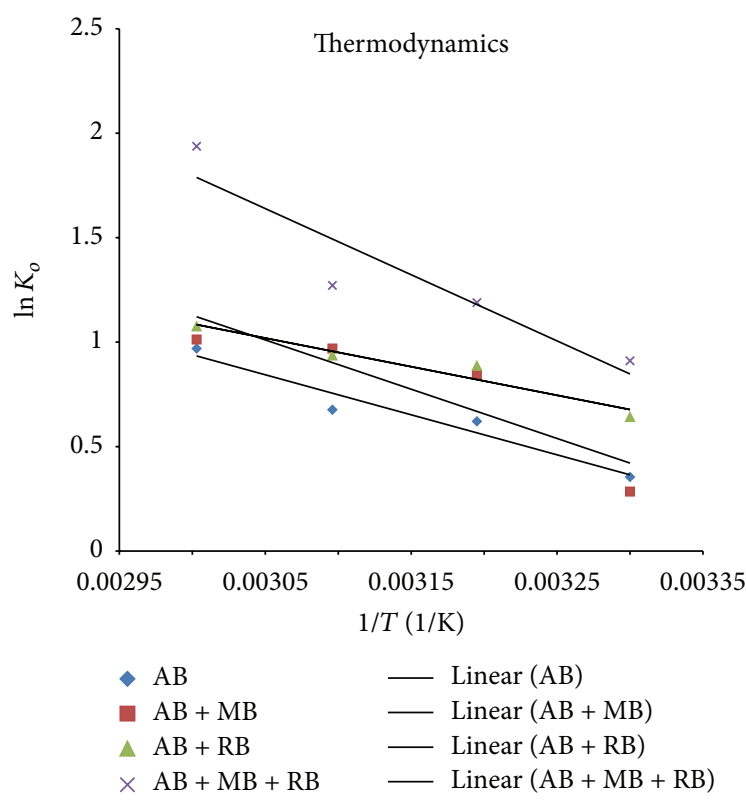

(b)

FIGURE 9: Effects of temperature (a) and thermodynamics (b) of adsorption of Acid Blue 161 on RSD.

physiosorption. However, this assertion does not rule out the possibility of chemisorption, as not all chemical interactions are by ion-exchange mechanism. The conformation of the adsorption processes to pseudo-second-order rate model, as stated earlier, suggests an element of chemisorptions in the process, particularly in the rate determining step. Positive value of $b_{T}$ implies that the adsorption processes were endothermic.

\subsection{Thermodynamics of Adsorption of Acid Blue 161 Dye on} $R S D$. The effects of temperature on the adsorptive removal of Acid Blue 161 in single and mixture systems were investigated by performing batch adsorption experiments at four different temperatures: 303, 313, 323, and $333 \mathrm{~K}$. The results are depicted in Figure 9. As clearly shown in the figure, the adsorption capacity, $q_{e}$, of RSD for Acid Blue 161 dye increased with increasing temperature in the single, binary, and ternary dye systems. The effect was, however, more pronounced in the ternary mixture than in others. With the increase in temperature, more dye molecules gained additional energy to overcome the energy barrier in chemisorption processes. Also, the increase in temperature must have resulted in a change in the morphology of the RSD adsorbent, leading to increased pore sizes and thereby allowing easier penetration of dye molecules [47].

The changes in free energy $(\Delta G)$, enthalpy $(\Delta H)$, and entropy $(\Delta S)$ of the adsorption processes were the thermodynamic parameters evaluated from the data obtained from batch adsorption experiments conducted at the different temperatures. The following equations were employed:

$$
\Delta G=-R T \ln K_{o}
$$

$$
\begin{aligned}
K_{o} & =\frac{q_{e}}{C_{e}}, \\
\Delta G & =\Delta H-T \Delta S .
\end{aligned}
$$

Therefore,

$$
\Delta H-T \Delta S=-R T \ln K_{o}
$$

In linear form,

$$
\ln K_{o}=\frac{\Delta S}{R}-\frac{\Delta H}{R T}
$$

where $K_{0}$ is the sorption distribution coefficient, $\Delta G$ $\left(\mathrm{KJmol}^{-1}\right)$ is the free energy of adsorption, $T$ (Kelvin) is the absolute temperature, $R$ is the universal gas constant, $\Delta H$ $\left(\mathrm{KJmol}^{-1}\right)$ is the heat of adsorption, and $\Delta S\left(\mathrm{~K} \cdot \mathrm{J} \cdot \mathrm{mol}^{-1} \mathrm{~K}^{-1}\right)$ is the entropy change.

Figure 9(b) shows the plots of $\ln K_{0}$ versus $1 / T$ for the adsorption of Acid Blue 161 in single and mixture adsorbate systems at different temperatures. The corresponding enthalpy change, $\Delta H$, and entropy change, $\Delta S$, obtained from the slopes and intercepts and the free energy changes, $\Delta G$, evaluated using (9) are presented in Table 3.

The change in Gibbs free energy, $\Delta G$, for the adsorption of the dye in all the four systems investigated is negative, ranging from -0.72 to $-5.36 \mathrm{~kJ} / \mathrm{mol}$. This is an indication that the sorption processes were spontaneous and thermodynamically feasible. In each system, the adsorption process became more feasible with increasing temperature (Table 3). Similarly, all the adsorption processes in the adsorbate systems studied were endothermic as the enthalpy change, $\Delta H$, for 


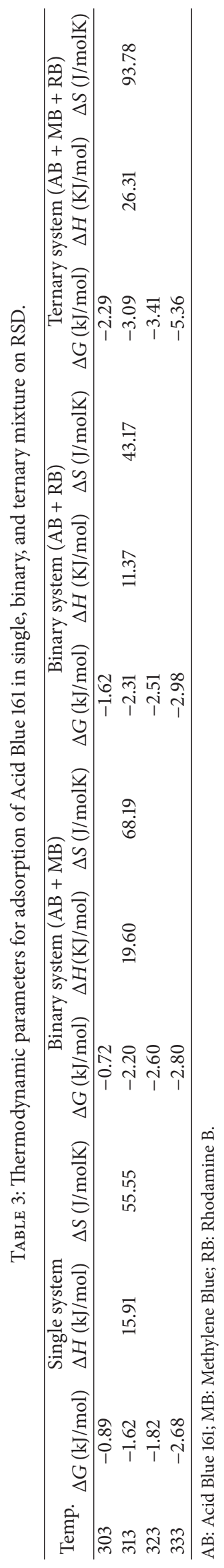


each of them is positive. This explains why the spontaneity of the processes increased with an increase in temperature as heat was absorbed in the course of the interaction between the dye and the surface of the adsorbent. The change in entropy, $\Delta S$, was positive for the four adsorption processes (Table 3). These positive values of $\Delta S$ portray increased randomness at the interface between RSD and the dye(s) in both the single and the mixture systems. Increased randomness after adsorption processes has also been reported in several studies [22$24,48,49]$. This suggests a significant alteration to the internal structure of the adsorbent resulting from these adsorption processes [44].

\section{Conclusion}

This present study shows that sawdust of Parkia biglobosa adsorbent was able to remove Acid Blue 161 from aqueous solutions in single and mixture adsorbate systems. The adsorption processes were all described by pseudo-secondorder kinetics while the three isotherm models (Freundlich, Langmuir, and Temkin and Pyzhev) have high correlation coefficients $(>0.9)$ in some cases, implying that at different stages the adsorption processes exhibit different characteristics which influenced the final mechanism. The Langmuir maximum monolayer coverage, $Q_{o}$, for the adsorption of Acid Blue 161 dye was lower in the single adsorbate system $(40.00 \mathrm{mg} / \mathrm{g})$ than in the two binary and ternary systems which have values of $100.00 \mathrm{mg} / \mathrm{g}$ and $94.34 \mathrm{mg} / \mathrm{g}$, respectively; hence, the mixture had a synergetic effect on the adsorption process. All the adsorption processes investigated were spontaneous and thermodynamically feasible as evident from negative $\Delta G$ values (ranging from -0.72 to $-5.36 \mathrm{~kJ}$ / $\mathrm{mol}$ ). They were endothermic ( $\Delta H$ range: $11.37-26.31 \mathrm{~kJ} / \mathrm{mol}$ ) and accompanied with increased randomness with $\Delta S$ values range of $43.17-93.78 \mathrm{~J} / \mathrm{mol} \cdot \mathrm{K}$.

\section{Competing Interests}

The authors declare that there are no competing interests regarding the publication of this paper.

\section{Acknowledgments}

The authors acknowledge the financial assistance rendered by Cape Peninsula University of Technology towards publishing this research.

\section{References}

[1] D. K. Singh and B. Srivastava, "Basic dyes removal from waste water by adsorption on rice husk carbon," Indian Journal of Chemical Technology, vol. 8, pp. 133-139, 2001.

[2] S. M. A. G. U. de Souza, L. C. Peruzzo, and A. A. Ulson de Souza, "Numerical study of the adsorption of dyes from textile effluents," Applied Mathematical Modelling, vol. 32, no. 9, pp. 17111718, 2008.

[3] B. Cheknane, M. Baudu, J.-P. Basly, and O. Bouras, "Adsorption of basic dyes in single and mixture systems on granular inorganic-organic pillared clays," Environmental Technology, vol. 31, no. 7, pp. 815-822, 2010.
[4] M. Makeswari and T. Santhi, "Removal of malachite green dye from aqueous solutions onto microwave assisted zinc chloride chemical activated epicarp of Ricinus communis," Journal of Water Resource and Protection, vol. 5, pp. 222-238, 2012.

[5] H. Ali and S. K. Muhammad, "Biosorption of crystal violet from water on leaf biomass of Calotropis procera," Journal of Environmental Science and Technology, vol. 1, no. 3, pp. 143-150, 2008.

[6] B. H. Hameed, R. R. Krishni, and S. A. Sata, "A novel agricultural waste adsorbent for the removal of cationic dye from aqueous solutions," Journal of Hazardous Materials, vol. 162, no. 1, pp. 305-311, 2009.

[7] K. R. Ramakrishna and T. V. Viraraghavan, "Dye removal using low cost adsorbents," Water Science and Technology, vol. 36, no. 2-3, pp. 189-196, 1997.

[8] A. El-Maghraby and H. E. El Deeb, "Removal of a basic dye from aqueous solution by adsorption using rice hulls," Global Nest Journal, vol. 13, no. 1, pp. 90-98, 2011.

[9] M.-S. Chiou and H.-Y. Li, "Equilibrium and kinetic modeling of adsorption of reactive dye on cross-linked chitosan beads," Journal of Hazardous Materials, vol. 93, no. 2, pp. 233-248, 2002.

[10] M. T. Sulak, E. Demirbas, and M. Kobya, "Removal of Astrazon Yellow 7GL from aqueous solutions by adsorption onto wheat bran," Bioresource Technology, vol. 98, no. 13, pp. 2590-2598, 2007.

[11] A. M. Mohammed, K. M. Dalia, and A. A. Enas, "Adsorption of basic dye from aqueous solution using mixture of agricultural solid wastes (Maw): isotherm, kinetic studies and process design," Journal of Advanced Science and Engineering Research, vol. 1, no. 1, pp. 76-97, 2011.

[12] F. A. Batzias and D. K. Sidiras, "Dye adsorption by prehydrolysed beech sawdust in batch and fixed-bed systems," Bioresource Technology, vol. 98, no. 6, pp. 1208-1217, 2007.

[13] S. Senthilkumaar, P. Kalaamani, K. Porkodi, P. R. Varadarajan, and C. V. Subburaam, "Adsorption of dissolved reactive red dye from aqueous phase onto activated carbon prepared from agricultural waste," Bioresource Technology, vol. 97, no. 14, pp. 1618-1625, 2006.

[14] E. Eren and B. Afsin, "Investigation of a basic dye adsorption from aqueous solution onto raw and pre-treated sepiolite surfaces," Dyes and Pigments, vol. 73, no. 2, pp. 162-167, 2007.

[15] Z. Aksu, "Application of biosorption for the removal of organic pollutants: a review," Process Biochemistry, vol. 40, no. 3-4, pp. 997-1026, 2005.

[16] I. Ali, “The quest for active carbon adsorbent substitutes: inexpensive adsorbents for toxic metal ions removal from wastewater," Separation and Purification Reviews, vol. 39, no. 34, pp. 95-171, 2010.

[17] I. Ali, M. Asim, and T. A. Khan, "Low cost adsorbents for the removal of organic pollutants from wastewater," Journal of Environmental Management, vol. 113, pp. 170-183, 2012.

[18] I. Ali, "Water treatment by adsorption columns: evaluation at ground level," Separation \& Purification Reviews, vol. 43, no. 3, pp. 175-205, 2014.

[19] S. Noreen, H. N. Bhatti, S. Nausheen, S. Sadaf, and M. Ashfaq, "Batch and fixed bed adsorption study for the removal of Drimarine Black CL-B dye from aqueous solution using a lignocellulosic waste: a cost affective adsorbent," Industrial Crops and Products, vol. 50, pp. 568-579, 2013.

[20] S. Sadaf, H. N. Bhatti, S. Nausheen, and S. Noreen, "Potential use of low-cost lignocellulosic waste for the removal of direct violet 
51 from aqueous solution: equilibrium and breakthrough studies," Archives of Environmental Contamination and Toxicology, vol. 66, no. 4, pp. 557-571, 2014.

[21] S. Nausheen, H. N. Bhatti, S. Sadaf, Z. Farrukh, and S. Noreen, "Equilibrium modeling of removal of Drimarine Yellow HF3GL dye from aqueous solutions by low cost agricultural waste," Journal of the Chemical Society of Pakistan, vol. 36, no. 1, pp. 177190, 2014.

[22] A. A. Olajire, A. A. Giwa, and I. A. Bello, "Competitive adsorption of dye species from aqueous solution onto melon husk in single and ternary dye systems," International Journal of Environmental Science and Technology, vol. 12, no. 3, pp. 939-950, 2015.

[23] A. A. Giwa, I. A. Bello, and A. A. Olajire, "Removal of basic dye from aqueous solution by adsorption on melon husk in binary and ternary systems," Chemical and Process Engineering Research, vol. 13, pp. 51-68, 2013.

[24] A. A. Giwa, M. A. Oladipo, and K. A. Abdulsalam, "Adsorption of Rhodamine B from single, binary and ternary dye systems using Sawdust of Parkia biglobosa as adsorbent: isotherm, kinetics andthermodynamics studies," Journal of Chemical and Pharmaceutical Research, vol. 7, no. 2, pp. 454-475, 2015.

[25] A. Giwa, A. Olajire, D. Adeoye, and T. Ajibola, "Kinetics and thermodynamics of ternary dye system adsorption on to melon (Citrillus lanatus) seed husk," American Chemical Science Journal, vol. 7, no. 1, pp. 7-25, 2015.

[26] A. A. Giwa, A. A. Olajire, M. A. Oladipo, M. O. Bello, and I. A. Bello, "Adsorption of ternary metal system onto the sawdust of locust bean tree (Parkiabiglobosa): equilibrium, kinetics and thermodynamics studies," International Journal of Scientific and Engineering Research, vol. 4, no. 6, pp. 1275-1296, 2013.

[27] O. A. Ekpete and M. J. Horsfall, "Preparation and characterization of activated carbon derived from fluted pumpkin stem waste (Telfairia occidentalis Hook F)," Research Journal of Chemical Sciences, vol. 1, no. 3, pp. 10-17, 2011.

[28] E. Demirbas, M. Kobya, E. Senturk, and T. Ozkan, "Adsorption kinetics for the removal of chromium (VI) from aqueous solutions on the activated carbons prepared from agricultural wastes," Water SA, vol. 30, no. 4, pp. 533-539, 2004.

[29] J. Singh, N. S. Mishra, Uma, S. Banerjee, and Y. C. Sharma, "Comparative studies of physical characteristics of raw and modified sawdust for their use as adsorbents for removal of acid dye," BioResources, vol. 6, no. 3, pp. 2732-2743, 2011.

[30] B. H. Hameed, D. K. Mahmoud, and A. L. Ahmad, "Equilibrium modeling and kinetic studies on the adsorption of basic dye by a low-cost adsorbent: Coconut (Cocos nucifera) bunch waste," Journal of Hazardous Materials, vol. 158, no. 1, pp. 65-72, 2008.

[31] V. Ponnusami, V. Gunasekar, and S. N. Srivastava, "Kinetics of methylene blue removal from aqueous solution using gulmohar (Delonix regia) plant leaf powder: multivariate regression analysis," Journal of Hazardous Materials, vol. 169, no. 1-3, pp. 119-127, 2009.

[32] Y. Yang, D. Jin, G. Wang, S. Wang, X. Jia, and Y. Zhao, "Competitive biosorption of Acid Blue 25 and Acid Red 337 onto unmodified and CDAB-modified biomass of Aspergillus oryzae," Bioresource Technology, vol. 102, no. 16, pp. 7429-7436, 2011.

[33] O. S. Bello, I. A. Adeogun, J. C. Ajaelu, and E. O. Fehintola, "Adsorption of methylene blue onto activated carbon derived from periwinkle shells: kinetics and equilibrium studies," Chemistry and Ecology, vol. 24, no. 4, pp. 285-295, 2008.
[34] Y. S. Ho, Adsorption of heavy metals from waste streams by peat [Ph.D. thesis], The University of Birmingham, Birmingham, UK, 1995.

[35] Y. S. Ho, G. McKay, D. A. J. Wase, and C. F. Forster, "Study of the sorption of divalent metal ions on to peat," Adsorption Science and Technology, vol. 18, no. 7, pp. 639-650, 2000.

[36] A. Gücek, S. Şener, S. Bilgen, and M. A. Mazmanci, "Adsorption and kinetic studies of cationic and anionic dyes on pyrophyllite from aqueous solutions," Journal of Colloid and Interface Science, vol. 286, no. 1, pp. 53-60, 2005.

[37] Y.-S. Ho, "Review of second-order models for adsorption systems," Journal of Hazardous Materials, vol. 136, no. 3, pp. 681689, 2006.

[38] I. Langmuir, "The adsorption of gases on plane surfaces of glass, mica and platinum," Journal of the American Chemical Society, vol. 40, no. 9, pp. 1361-1403, 1918.

[39] H. M. F. Freundlich, "Über die adsorption in lösungen," Zeitschrift für Physikalische Chemie, vol. 57A, pp. 385-470, 1906.

[40] M. I. Temkin and V. Pyzhev, "Kinetics of Ammonia synthesis on promoted iron catalysts," Acta Physiochim. URSS, vol. 12, pp. 327-356, 1940.

[41] M. A. MohdSalleh, D. K. Mahmoud, N. A. B. Awang Abu, W. A. W. AbdulKarim, and A. Idris, "Methylene blue adsorption from aqueous solution by Lungsat(Lansium domesticum) peel," Journal of Purity, Utility Reaction and Environment, vol. 1, no. 10, pp. 272-292, 2011.

[42] A. L. Prasad and T. Santhi, "Adsorption of hazardous cationic dyes from aqueous solution onto Acacia nilotica leaves as an eco friendly adsorbent," Sustainable Environment Research, vol. 22, no. 2, pp. 113-122, 2012.

[43] K. Fytianos, E. Voudrias, and E. Kokkalis, "Sorption-desorption behaviour of 2,4-dichlorophenol by marine sediments," Chemosphere, vol. 40, no. 1, pp. 3-6, 2000.

[44] L. C. Juang, C. C. Wang, C. K. Lee, and T. C. Hsu, "Dyes adsorption onto organoclay and Mcni-41," Journal of Environmental Management, vol. 17, no. 1, pp. 29-38, 2007.

[45] M. Ajmala, A. H. Khana, S. Ahmada, and A. Ahmadb, "Role of sawdust in the removal of copper (II) from industrial wastes," Water Research, vol. 32, no. 10, pp. 3085-3091, 1998.

[46] M. Sekar, V. Sakthi, and S. Rengaraj, "Kinetics and equilibrium adsorption study of lead(II) onto activated carbon prepared from coconut shell," Journal of Colloid and Interface Science, vol. 279, no. 2, pp. 307-313, 2004.

[47] V. K. Verma and A. K. Mishra, "Kinetic and isotherm modeling of adsorption of dyes onto rice husk carbon," Global Nest Journal, vol. 12, no. 2, pp. 190-196, 2010.

[48] B. S. Inbaraj and N. Sulochana, "Use of jackfruit peel carbon (JPC) for adsorption of rhodamine $\mathrm{B}$, a basic dye from aqueous solution," Indian Journal of Chemical Technology, vol. 13, no. 1, pp. 17-23, 2006.

[49] A. J. Ahamed, V. Balakrishnan, and Arivolis, "Kinetic and equilibrium studies of Rhodmne B adsorption by low cost activated carbon Arch," Journal of Applied Sciences Research, vol. 3, no. 3, pp. 154-166, 2011. 

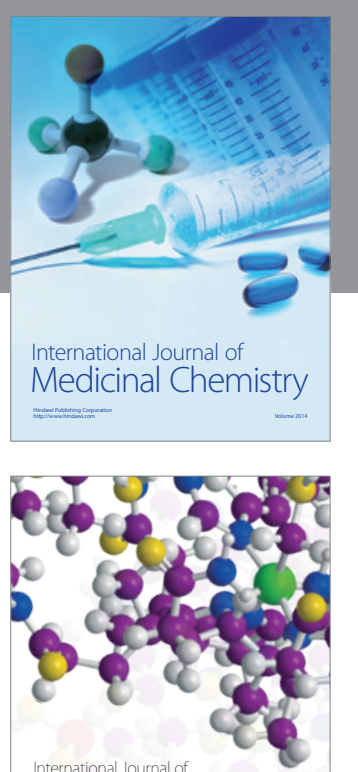

Carbohydrate Chemistry

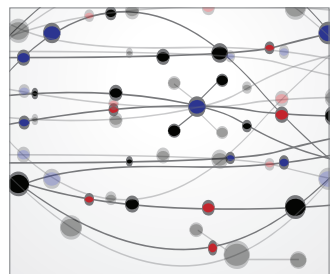

The Scientific World Journal
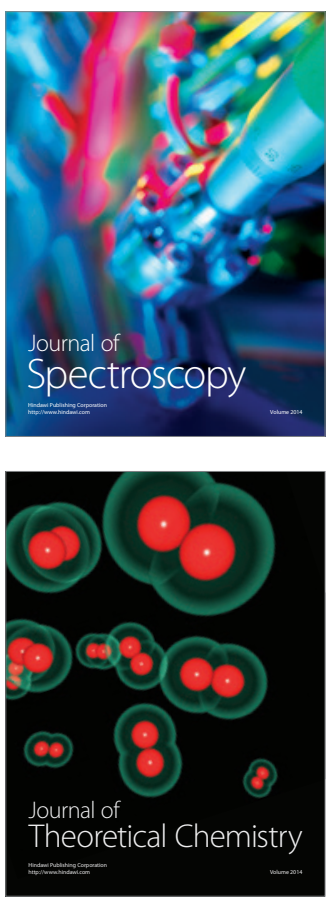
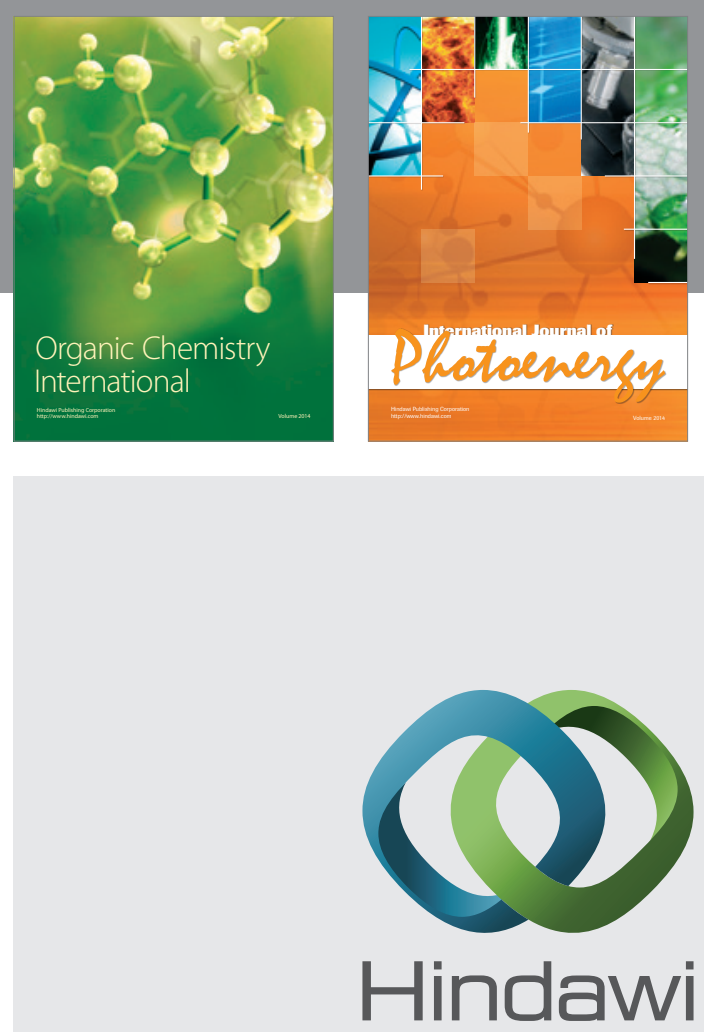

Submit your manuscripts at

http://www.hindawi.com

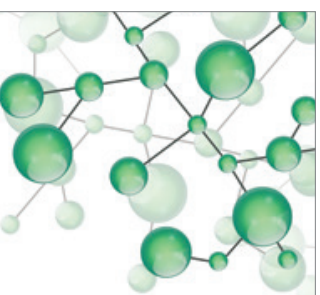

International Journal of

Inorganic Chemistry

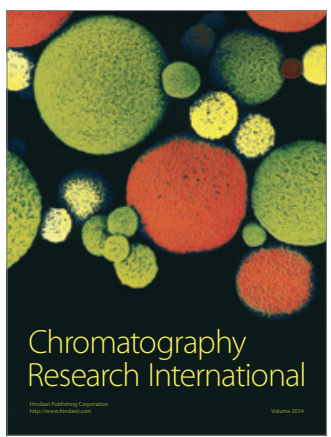

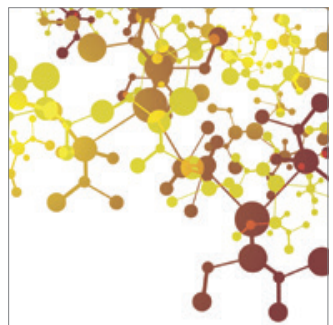

Applied Chemistry
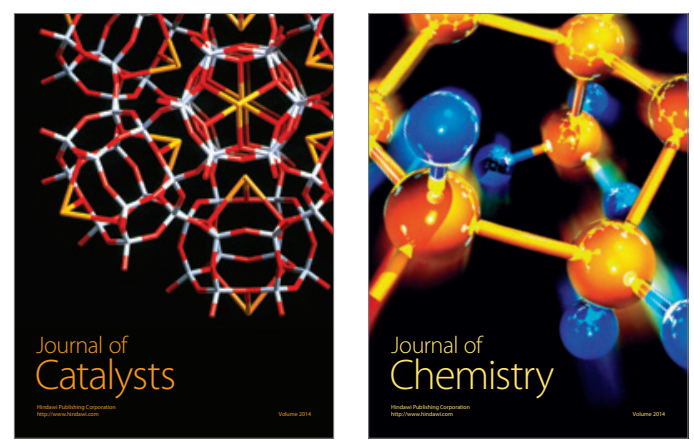
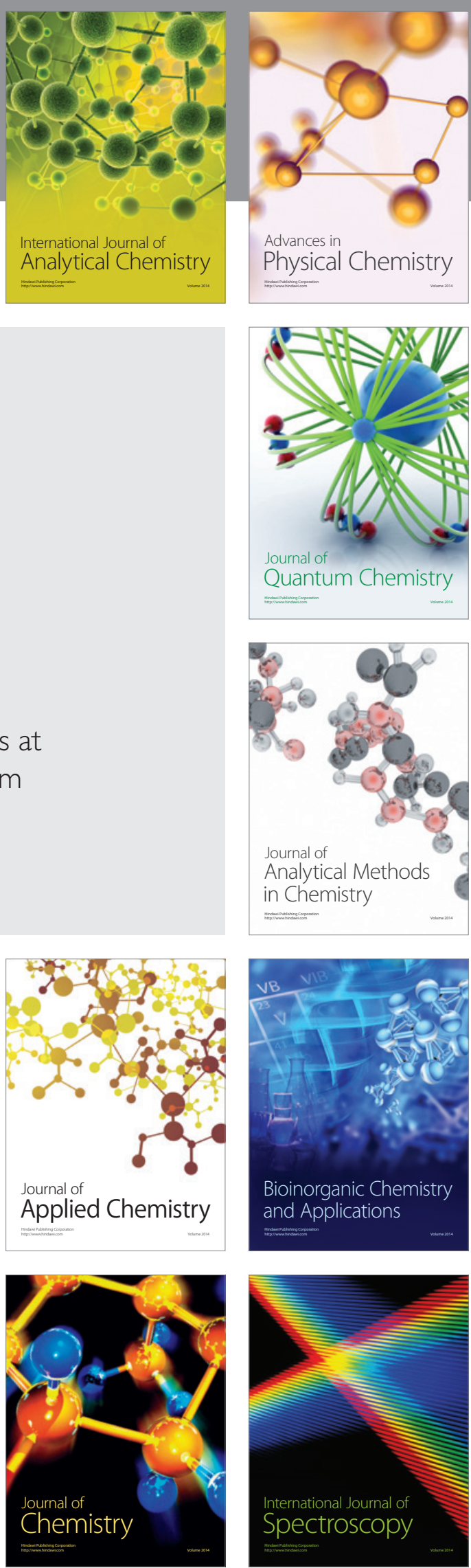